\title{
Exploration on the FLAC3D software in the Teaching of Petroleum Drilling Engineering Rock Mechanics Course
}

\author{
Zhao Baoyun ${ }^{a}$, Huang Linqing, Wu Tongqing \\ ${ }^{1}$ School of Civil Engineering and Architecture, Chongqing University of Science \& Technology, \\ Chongqing, 401331, China \\ aemail: baoyun666@163.com
}

\begin{abstract}
Keywords: Numerical Simulation Demonstrates; Rock Mechanics; Practice Education
\end{abstract}
\begin{abstract}
The rock mechanics course is an engineering discipline which has strong practical and theoretical. According to the lagging of rock mechanics experiment teaching or lacking of experimental teaching funds and difficulty of the combination theory with practice teaching problems, in this paper we put forward a teaching method that combining with numerical simulation technique and theoretical knowledge, in the teaching process of petroleum drilling engineering rock mechanics, the software FLAC ${ }^{3 \mathrm{D}}$ was carried out to demonstrating rock creep process and indoor creep test results were compared. The teaching method which helps students enhance understanding the rock mechanics related knowledge, and the students' theoretical level and practical skills were also improved. At the same time, using $\mathrm{FLAC}^{3 \mathrm{D}}$ numerical simulation demonstrates technique is a beneficial supplement of rock mechanics experiment teaching.
\end{abstract}

\section{Introduction}

Rock mechanics is a limited courses in colleges and universities in civil engineering, hydraulic engineering, petroleum engineering, mining engineering, and many other specialty, due to the rock mechanics course is one of courses to be full practical and also is a course in close connection with the actual needs of production, that requires students to deep understanding of rock mechanics theory, and be able to contact the actual interpretation of rock engineering to explaining the instability of rock engineering and failure problems. For petroleum drilling engineering students, rock mechanics experiments not only including the uniaxial compression test, conventional triaxial test, split test and three-point bending test that can reflect rock basic physical and mechanical properties of failure and instability, but also including those relating to the borehole wall long-term stability of rock creep experiment. The basic mechanical properties of the rock mechanics experiments can be achieved through the indoor experiment teaching, but rock creep is the strain changes in the relationship over time under constant loads, due to the longer time required for the experiment, the lack or limited indoor experimental conditions, and rock non uniform , nonlinear, and failure behavior, ground pressure and other factors, it is very difficult to achieve long-term result on the small sample indoor experiment, and suitable for teaching in this regard the data files (including photos, charts, videos, etc.) is sorely lacking in ordinary laboratory, even these experiments can be achieved due to high cost and do not have the students' observations, usually are not in the experimental teaching range. By the demonstrated method of numerical simulation technology for rock mechanics numerical experiment is undoubtedly one of the best ways to solve this problem.

With the rapid development and progress of numerical simulation methods and computer program, some excellent numerical simulation software was used in rock mechanics, such as FLAC $^{3 \mathrm{D}}$, and so on. Numerical simulation technology to demonstrate rock mechanics problems, the characteristics of this teaching method is easy to teach, easy to learn and easy to operate, and more accusative and the computer can break the time and space limit, anytime and anywhere to carry out numerical simulation model to demonstrate, by numerical simulation technology can reproduce the failure phenomenon of rock material, so it is not only retains the intuitive advantages of physics experiments, but to overcome the indoor experimental shortcomings of the difficult observations, 
the high repeat cost, long cycle, not easy to achieve, and also be able to get a lot of important information cannot observed in the actual laboratory, such as drilling surrounding rock stress and strain change and failure process. And most of the simulation software with visualization and animation techniques, to some extent, can makes dull experiment teaching becomes flexible and vivid to cultivate students' independent initiative to carry out research capacity and skills.

In this paper, in rock mechanics teaching process we introduced FLAC ${ }^{3 \mathrm{D}}$ to dome rock creep test that support by Chongqing University, and the creep test results and numerical simulation tests were compared in teaching, that stimulate the students' learning interest, to deepen students understanding and interpretation of rock mechanics and the Improve the students' theoretical level and practical skills.

\section{FLAC $^{3 D}$ Demonstrates Rock Mechanics Problems}

The FLAC $^{3 \mathrm{D}}$ is a three-dimensional finite difference program that cans mechanical characteristics simulation and plastic flow analysis of soil, rock and other materials. Compared with the real rock mechanics test, numerical simulation technology has the advantages of using the flexible, simple and convenient, can greatly reduce the cost, and its simulation process is divided into the following steps:

- The object of research and analysis, explicit calculation purposes and plans to solve the key problem, select the numerical methods and simulation software, to determine the modeling program.

- The establishment of a computational model, to select constitutive model and parameter determination.

Rock is not a kind of isotropic material, not only stress level affects its performance, the mechanical process, so-called stress path, also influence its stress-strain relationship. Therefore, modeling should be based on the actual engineering to determine the constitutive relation and assigned to the corresponding mechanical parameters; the mechanical parameters are often derived from the on-site test.

- To determine the boundary conditions and initial conditions.

Rock mechanics problems, mostly under certain initial conditions, such as initial ground stress, we should be based on the actual situation to apply an appropriate initial conditions.

- To determine the simulation loading levels.

- Determine the convergence criterions.

- Study various aspects of simplified reasonable, otherwise it should be adjusted to the modeling and computational model parameters.

- To determine finishing processing methods and results and analysis programs.

\section{The Creep Test Examples Demonstrate}

In order to better make the rock creep clear to the students, numerical simulation of FLAC ${ }^{3 \mathrm{D}}$ that was supported by Chongqing University was used to demonstrate the rock creep process, and the results were compared with real experimental data, the software can simulate the process of rock creep and fracture propagation process, easy students observing learning.

\section{A. Numerical Simulation Demonstration Model Building}

The template is used to format your paper and style the text. All margins, column widths, line spaces, and text fonts are prescribed; please do not alter them. You may note peculiarities. For example, the head margin in this template measures proportionately more than is customary. This measurement and others are deliberate, using specifications that anticipate your paper as one part of the entire proceedings, and not as an independent document. Please do not revise any of the current designations.

FLAC $^{3 \mathrm{D}}$ numerical demonstration with laboratory tests of rock samples for comparison, simulation specimen model size of $10 \mathrm{~cm}$ (Y direction), $5 \mathrm{~cm}$ in diameter (the same size as indoor 
specimen), were divided into 1000 units and 1111 nodes. At the bottom of the model Y direction displacement was constraint, the top applied uniaxial compression creep test of the corresponding load, the indoor rock specimen is shown in figure 1 below and the corresponding numerical demonstration calculation mode is shown in figure 2. Numerical simulation demonstration loads, in turn, is 28.03 MPa, 33.63 MPa, 39.24 MPa, 44.84 MPa and 50.45 MPa.

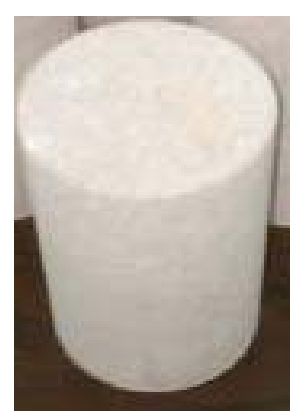

Fig.1. Rock specimen

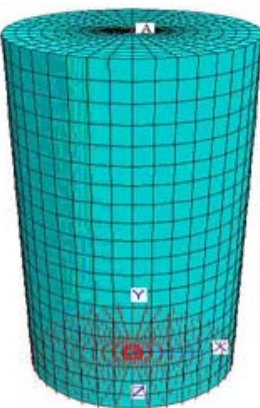

Fig.2.Numerical model

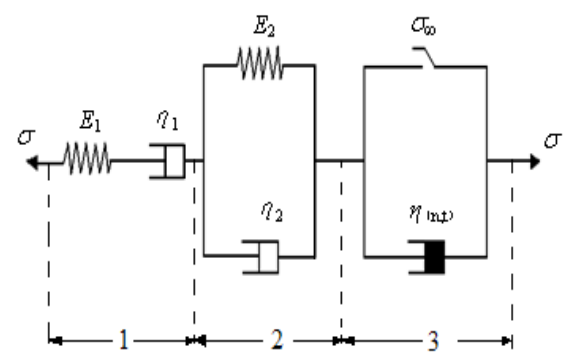

Fig.3.Nonlinear creep model

\section{B. Constitutive Model Selection}

In order to show students a real creep and failure process, in the process of teaching, a nonlinear creep constitutive model by the author himself derivation was introduced, the creep constitutive model as shown in figure 3 and the creep equation as shown in formula 1 . The model can well reflect the instantaneous loading strain of the rock sample, attenuation creep, constant creep and accelerated creep process of three stages of creep curve, at the same time for the characterization of extension variation characteristics of plastic zone in the process of teaching demonstration the Mohr - Coulomb yield criterion was used.

$$
\left\{\begin{array}{c}
\varepsilon=\frac{\sigma_{0}}{E_{1}}+\frac{\sigma_{0}}{\eta_{1}} t+\frac{\sigma_{0}}{E_{2}}\left(1-\exp \left(-\frac{E_{2}}{\eta_{2}} t\right)\right) \quad\left(\sigma \leq \sigma_{\infty}\right) \\
\varepsilon=\frac{\sigma_{0}}{E_{1}}+\frac{\sigma_{0}}{\eta_{1}} t+\frac{\sigma_{0}}{E_{2}}\left(1-\exp \left(-\frac{E_{2}}{\eta_{2}} t\right)\right)+\frac{\sigma_{0}-\sigma_{\infty}}{\eta_{3}} t^{n} \quad\left(\sigma>\sigma_{\infty}\right)
\end{array}\right.
$$

\section{Demonstration}

Using the above nonlinear creep constitutive model (as shown in formula 1), the numerical simulation uniaxial compression creep test of rock specimen was demonstrated by the FLAC3D software. Similar with indoor experiment, the loads applied on the model in the demonstration process were 28.03 $\mathrm{MPa}$, 33.63 $\mathrm{MPa}$, 39.24 MPa and 44.84 MPa and 50.45 MPa in turn, and creep load duration per level is the same as the indoor test of time. The rock uniaxial compression creep simulation test demonstrate results shown as figure 4, in the figure shows the simulated specimen creep displacement contour and the creep curve. Figure 5 is the laboratory creep test results curve of the rock specimen, from which we can see that simulation results and laboratory test results of rock creep level variables or creep law at each levels are very similar. FLAC3D can be regard as a good tool to assist the rock mechanics teaching.

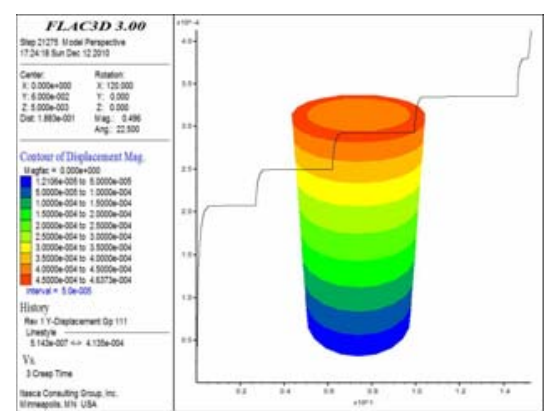

Fig.4. The curve of uniaxial compression creep test simulation

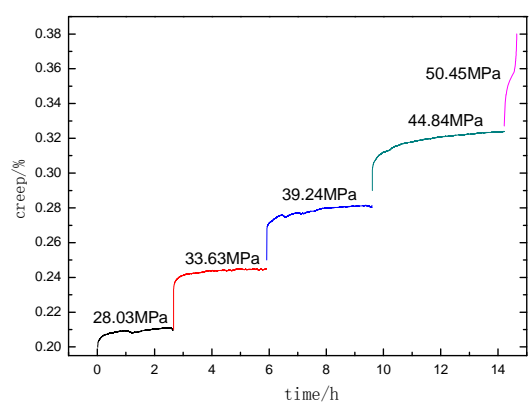

Fig.5. Tndoor creep test curves

Figure 6 is the picture of plastic zone extension that was judged by Mohr - Coulomb yield criterion, it can be seen that specimen damage for the specimens with axial crack cleavage, and at the bottom of the specimen it appears local tension damage, which was very similarly as the uniaxial compression creep test fracture. Figure 7 is the picture of rock spacemen creep damage 
figure.

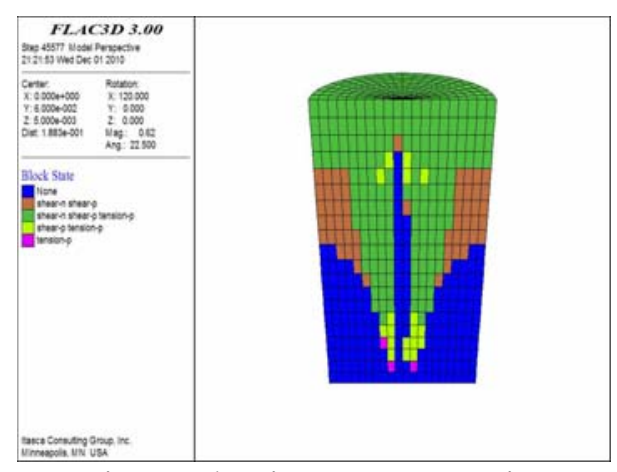

Fig.6. Plastic zone extension

\section{The Teaching Effect}

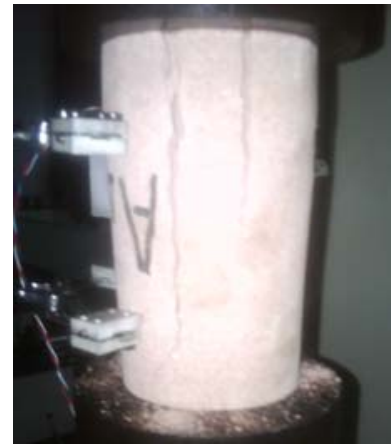

Fig.7. Rock sepicemen creep damage

Through the above demonstration, can be very intuitive to show rock deformation under constant loads with real time the development process as well as different time rock rupture process, help students better understand the creep properties of the rock and achieve experimental teaching goal. Numerical simulation technology combined with rock mechanics teaching can greatly stimulate students' learning interesting, to deepen the students correct understanding and mastery of rock mechanics problems, improve the students theoretical level and practical skills.

\section{Conclusion}

Aim to solve the rock mechanics teaching problems of the lagging behind of experimental, experimental teaching financially and the difficulty to combining theory with practice. In this paper we introduced FLAC3D numerical simulation technology and applied it into the rock mechanics teaching, and put the author's own derivate creep constitutive model into the simulated demonstration, meanwhile, the demonstration results were compared with indoor test curves and pictures, which expand the horizons of students, to stimulate students' interest in learning rock mechanics courses, make students to truly feel the charm of rock mechanics and achieved good teaching effect. Research achievement of this paper can provide teaching reference for rock mechanics and other course.

\section{Acknowledgement}

This research is supported by the China Metallurgical Society of Education Educational Research planning issues (YZG09027), the Key Laboratory of New Technology for Construction of Cities in Mountain Area (Chongqing University) and the Education Reform Project of Chongqing University of Science \& Technology (CK201128, CK201130).

\section{References}

[1] ZHANG Yi ping, LIU Yong, CAO Yun qing. Promoting Rock Mechanics Teaching Through Numerical Test[J]. Journal of Guizhou University (Natural Sciences) , 2007,24(4):436-440.

[2] Zhang Xiaojun, Zheng Huaichang. Promoting rock mechanics classroom teaching through numerical simulation result demonstration[J]. The Chinese modern education equipment ,2012,145(9):47-49.

[3] HUANG Mingkui. Exploration on the Numerical Experimental Teaching of the Course Rock Mechanics [J]. Journal of architectural education in institutions of higher learning , 2009,18(4): :129-132

[4] Huidong-Cao, Ying-Yang, Lunchu-Zheng. Deepening the reform of practice teaching system and students innovation and cultivating students ' abilities of innovation[J].China Higher Education, 2011 (11)47-48.(In chinese) 